\title{
CONSIDERATIONS REGARDING THE LOCATION AND THE ROLE OF ORGANIZATIONAL CULTURE IN THE ROMANIAN MILITARY ENVIRONMENT
}

\author{
Gabriela-Florina NICOARĂ \\ "Carol I" National Defence University, Bucharest, Romania \\ gabriela.nicoara.cj@gmail.com \\ Sorin Gheorghe PÎNZARIU \\ "Nicolae Bălcescu" Land Forces Academy, Sibiu, Romania \\ sorinpinz@yahoo.com
}

\begin{abstract}
Nowadays organizational human capital is an essential resource for any organization. Moreover, it gives the organization a significant competitive benefit. In that light, the aim of this article is to highlight how the activities carried out in the framework of human resources management influence the organizational culture in the military environment. Furthermore, our intention is to underline how the organizational culture within the military institution gets valences and inflection in relation to the practices of management which are implemented within the component of the human resources of the Romanian Army. The main methods we used in the present research were the personal observation and the study of the evidence.
\end{abstract}

KEYWORDS: human resources, management, organizational culture

\section{Introduction}

Managing the human resource within an organisation, whether civilian or military, against the backdrop of the challenges of the $21^{\text {st }}$ Century, represents a real provocative challenge. Until not long ago, when we were talking about the established objectives of the human resource component, we were widely taking into consideration the functional side of the field. We were focused on the employment of the available spots, on keeping a rigorous record of worked hours, and on abiding by "Labour Code" - the main legal framework within human resource field. Nowadays, we are forced to accept all the transformations occurred in the society and to change our behaviour in order to fulfil all the identified necessities.
The accelerated development of technology and its implications in private and in internal life (from the media's impact on the whole populations and up to the pressing need to have a minimum digital competence in order to become successful in accessing a job), a great variety of jobs within the professional field, the easiness of professional migration (from one field to another) are just a few arguments in order to support the need to adapt human resource to the reality.

At the organizational level, we are struggling with the coronavirus pandemic. The novelty of this challenge and the speed at which events follow, force us, in addition to the previous professional routine, to reinvent ourselves by training new skills, 
working to develop new habits, all of this in order to maintain a balance within the professional organization.

\section{Methodology}

The paper aims to highlight the importance of the military organizational culture within the army, and to underline the relationship between the human resources management and culture manifestations inside the military environment.

The article was written based on:

- A literature review relevant for organizational culture from social and management perspectives.

- Empirical research based on personal observation.

\section{The Place of Organizational Culture within the Romanian Military Enviroment}

Nowadays, the human resource within the military organization is in the middle of a development process. Hopefully, it will gain a new status of human capital and it will be seen as the critical resource of the army in the process of becoming a successful and competitive organization. "Human capital" refers to employees who "contribute to the organization with commitment, capabilities, knowledge and experience" (Mayo, 2014, p. 28). In this direction, the way this resource is understood and managed is a starting point in ensuring functionality and achieving organizational performance.

The basic premise from which we start in our approach to provide an appropriate interpretation to the organizational culture in the military environment is that the management of human resource is the attribute of structures specialized in personnel management. Moreover, the military's values, behaviour, and beliefs are fundamental elements of organizational culture and a proper management of these facilitates management practices within the human resources field.
In this direction, military organizational culture is closely linked to working life of Romanian soldiers. In addition, it has to define its place within the human resources component and to develop itself as a distinguish field of human resources domain.

\section{The Identity of the Organizational Cultural in the Military Environment}

One of the most accessible definitions, from an understanding point of view, finds a link between organizational culture and "how people act/make things work" (Senyucel, 2009, p. 44) within an organization. Thus, the translation of values, artefacts, beliefs, employee behaviour, in fact, of a significant number of elements which act under the name of organizational culture is a form of response to the needs and requirements of the organizational entity. Each individual activity within an institution, in particular and alongside others, in the community, contributes to the achievement of the organizational objectives. The organizational culture represents a common interest point of several disciplines (anthropology, psychology, sociology, etc.). In term of this, it was given different types of definitions.

Along with the start of the crystallization process, most points of view have proved to converge in a few elements.

First of all "the organizational culture involves concepts and behaviours" (Erhart, Schneider, Macey, 2014, p. 130), symbols, myths, practices, communication channels. Moreover, it manifests itself throughout the organization, generating functional relationships with all internal structures. Also, it is "subjective and expressive" (Erhart et al., 2014, p. 130), each organizational culture, in particular, has an individual note. Furthermore, it reiterates the manifestations of individual behaviour, representing a full corridor of aspects that had been translated from the life of the organization. Among the widely accepted elements, there is also 
its anchoring in the history and traditions of the organization. Each generation of employees or the organization's career development stage leaves its mark on the culture within the organization. Passing the organizational culture from the old employees to the new members, both through formally and informally aspects, is extent and uniqueness that are also commonly accepted.

When we are talking about organizational culture within the military environment, we have to admit that its identity id determined or, at least, influenced by a significant number of factors. Some of them, we elect to remind: the history of the Romanian Army, great personalities and leaders of the past time, the typology of the military organization, the hierarchical organization, the implemented management, the level of dependence on tech and technology, etc. All these factors, and not only they, have a significant influence on the organizational culture and, consequently, on the values promoted inside.

Within the military organizational culture there can be seen a few features that distinguish it significantly from other cultural aspects in the Romanian society. This shows significant stability despite the many changes in the army. Practices, symbols, communication channels, types of behaviour have been constantly present. Its expressiveness gives an identity note to the military organization, customizing itself through a well-defined place in the Romanian society. Furthermore, the military organizational culture is a carrier of traditions, being firmly anchored in the history of the Romanian people. The values and the rules of such a culture are difficult to change and their influence at the military organization level is much stronger than it is apparently perceived. By its easiness with which it is passed on to the new soldiers accepted in the system, ensures perpetuation of the internal values and traditions.
The adaptation the soldiers are going through, the process of accepting the internal values is sustained and facilitated by the transmissibility and the stability of the organizational culture. This represents the way of learning the values and the behaviour of the organization (formally regulated and informally perpetuated). It is true that the new employees promote their own values which often contradict those of the Army. However, this feature of organizational culture represented by promoting unambiguous messages about the values accepted internally through its own culture makes new soldiers understand, in a relatively short time, the need to complain about the new requirements of the informal working side.

Together with the formal rules imposed by a legal framework that sets out professional directions, the organizational culture also encourage rules and norms in the organizational environment. It also facilitates the clarifications, both on the side of fulfilment of the duties and on the status and roles assumed by the integration into the military organization.

In the literature, we find the idea that "the strong organizational cultures strengthen organizational performance by using their high values and ideals, resulting high levels of commitment and effort on the part of members. They also provide/build identity and significance to the organization. Such cultures direct and shape the behaviour of those involved." (Chandler, 2018, p. 1).

We hold that the Romanian military organization benefits from a solid organizational culture that is firmly shaped and that it is an important prerequisite for the consolidation of the organizational performance. Calling for accepted goals and values which were already internalized and which are, now, in the collective mind of the organization, the level of commitment of the staff involved increases significantly. Moreover, talking about awareness of the organizational identity, the significance of 
the profession is accentuated by giving military employee a sense of belonging to and even identification with the organization in which they work.

In a strong organizational culture, it is much easier to direct members ' behaviour and the benefits of proper management become visible.

So far, we have pointed out the main features of organizational culture and, in particular, military culture, arguing for the need to give attention to it and to move it from a secondary position to the front line. Our intention is also to emphasize the need for a regular evaluation and a continuous follow-up the organizational culture. We consider that this activity must be done by a structure or a specialist prepared on this stage.

Moreover, we believe that these tasks have to be parts of the human resources activities. We admit that the national Military Centre for Psychology and Health Command directly under the General Directorate for Human Resource Management is undertaking consistent efforts "with the intention of developing policies and regulations in the area of operational psychology, psychological assistance, socio-behavioural analysis, sociological and psychological research" (Mărgineanu, 2018, p. 33).

However, we may deem that to establish an operational link between the structures under this centre and those with explicit responsibilities in the area of personnel management is appropriate and necessary.

This connection must be established in order to use the military organizational culture, with its particular and specific elements, in ensuring functionality, making better the management practices and improving performance across several branches in the human resources component of the military organization.

\section{The Relationship between Human Resources Management and the Organizational Culture}

Within the military organization, we recognize the basic mission of the human resources component is to ensure, as a priority, compatible human resource with the specific requirements of the field. The fulfilment of the established objectives within the human resources management implies the development and the implementation of compatible politics and practices of management with the fundamental strategy of the military organization.

We know that until not long ago, the activities carried out within the personnel area were mainly focused on functionality, achievement of organizational objectives and performance. Nowadays, the development of the society in terms of professional area, forces the Army to conduct its management in order to assure and provide an optimal level of professional satisfaction.

The wide range of existing occupational bearings, increased mobility in terms of job change, easiness of re-training, unhindered access to the training of new skills and attractiveness of the working conditions offered by different companies are just a few issues that come to support the argument for the need to adopt an appropriate attitude toward the human resource of the Army.

The soldier represents the core of the human resources management. $\mathrm{He}$ is the active entity within the Army. The activities of running and controlling the personnel represent the territory of interest of human resources management but the values, ideas, the behaviour of their soldiers are formed in the organizational culture specific to the military environment.

Taking into account the fundamental mission of the human resources component within the military organization, we believe that human resources management (HRM) is the interface between the Romanian 
society and the military system. For example, HRM identifies personnel needs, translates them into requirement for the future human resource and promotes them as minimum / desirable requirements - at the time of recruitment of the candidates to the military profession. The transformative processes present within the military entity, under the auspices of the volatile security environment, oblige the human resources component to rethink how to identify its personnel needs. We consider human resource management as being a flexible and highly adaptable system, characterised by a set of processes that are inclusive (by accepting models from the society and, as well, giving models to the society). Moreover, we believe that it should take into account, in the process of identifying the requirements of personnel, the analysis / auditing of the organizational culture. Given this two-way influence relationship between human resources management and the military organizational culture, we consent the need to highlight some of the features that define it. Thus, a first feature of this is reciprocity. On the one hand, the management practices implemented are reflected, through various impacts, in changes in the structural elements of the organizational culture. On the other hand, changing an internal value entails new requirements related to the management if human resource.

In this relation, we can talk about a symbiotic evolution between the two elements. This mutually beneficial coexistence builds lasting functional relationships. Naturalness can be included in the category of traits, the relationship between the two elements being carried out naturally, without the obligation of obvious intentions from the outside.

If we acknowledge the existence of the relationship between military organizational culture and human resources management, the need to analyse and evaluate organizational culture in order to understand it as fully possible becomes stringent. It is true that the values within the organizational culture are a structural element of the culture but not everything should be reducing to their empirical identification. In this term, many studies had been done. A few of them had as a final purpose the development of a viable tools for culture analysis within an organization (example: "Competing Values Framework" 1999, "Organizational Culture Questionnaire" - 1990, "The GLOBE study" - 2004) (Chandler, 2018, p. 15). The aforementioned studies were developed around the specificity of the studied organization. Therefore, they had a few limits.

All in all, we admit the importance, the necessity and the usefulness of the analyses of the organizational culture within the Army.

\section{Aspects of the Organizational Culture within the Human Resources Component}

In order to be able to understand how organizational culture is reflected in managerial practices within the human resources component, we considered appropriate to stop on a few examples. The organizational culture directly influences the image that a soldier has about himself, about his job and his responsibilities given by the occupied function. The practices developed by the organization, the values and behaviour involved in the process of adapting, professional habits and ceremonies, and formal framework in which all these manifestations develop in the soldiers' mind a representation of his profession and his workplace.

A part of human resources management that has a particular relevance in ensuring the quality of the human resources in the army is personnel recruiting. As a gateway for potential soldiers into organization, the entire recruitment activity must be focused on 
attracting and admitting the personnel who proved to be as compatible as much possible with the requirements of the military organization. In order to be able to perform within the army, the employee must accept, and desirable on the basis of intrinsic motivation, the values promoted within the organizational culture.

The regular analysing of the constancy of the organizational culture in the military environment and the underline of the changes appeared inside should be an essential activity in order to give the army a compatible human resource. A candidate should have compatible or easy converting values to the culture he will be a part of. An applicant whose personal values are compatible with those circulated within the military organization will show a growing desire to stay within the organization (thus improving the staff retention segment). Moreover, work satisfaction, personal fulfilment regarding profession will become an important prerequisite in its performance in the medium to long term. In this way, among the Romanian soldiers, we will be able to talk about high-performing decision makers, dedicated leaders or people whose profession is suitable for them.

We believe that this match between the main values of organizational culture and the ones that soldiers have represents significant advantages for the entire entity. The objectives set within the military units and once stablished at the strategical level will be much easier to achieve and will be fulfilled at a higher level of performance by dedicated, competent and entire-committed soldiers.

Calling the ramifications of the improving compatibility between the organization's assets and the values of the soldiers we identified a significant number of advantages on the both sides. The aforementioned compatibility could be capitalized, in medium to long term, on real benefits on both sides, as can be seen in the table below:

Table no. 1

Advantages of compatibility between individual and organizational values

\begin{tabular}{|c|c|}
\hline $\begin{array}{c}\text { Identified advantages - } \\
\text { from the soldiers perspective }\end{array}$ & $\begin{array}{c}\text { Identified advantages - } \\
\text { from the organizational perspective }\end{array}$ \\
\hline Job satisfaction & $\begin{array}{c}\text { Increases retention of personnel, } \\
\text { improving the image of the military career }\end{array}$ \\
\hline Increased motivation, professional commitment & Devoted personnel \\
\hline Professional performance & Performing high standards of tasks \\
\hline Professional stability & Skilled employees \\
\hline Developing solid professional skills & Resilience \\
\hline
\end{tabular}

Another activity field within the human resources component is the one defined by the actions taken to detaining personnel within the military organization the retention of the personnel in the Army. It is true that financial motivation takes precedence over other aspects in choosing a career, most of the time. It is also true that financial incentives, favourable working conditions, material compensation (business vehicle, mobile phone, fuel settlement, rent payments, work housing) are important factors in the balance of choosing a job. They are not the only levers by which staff can be attracted, actively and productively kept within the military organization. In this bureaucratic field where Army acts, hypothetical financial incentives cannot be granted discretionally. This requires the design and implementation of regulated and validated legal mechanisms also integrated into the existent framework. From a time point of view, such an activity requires a significant amount of time.

Also, if we take into account the financial resources annually planned to be used by the Army, we see the increased importance given to equipping military 
structures with techniques and armaments in contrast to financial stimulation of military personnel.

In this context, where the military organization does not have the necessary levers to initiate staff strategies centred on financial incentives, the military organizational culture, through its consistency and specificity, can provide fertile ground for the retention of military personnel within the organization.

The sense of belonging to a strong professional organization with a set of welldefined values, a tradition that has made its value known to society and which through professional behaviour promoted internally, proves performance, both at individual and organizational level, offers an attractive prospect in terms of a possible long-term profession. Furthermore, the loss of human resources, the disappearance from key positions of some leaders in which the organization invested significant resources, can be consider the beginning of a real crisis. Although, in many cases the effects of staff gaps are not immediate, in the long term, the organization may present syncope at functional level. We deem that a strong organizational culture is the fertile ground for a high degree of retention of personnel within the military organization.

\section{Conclusions}

It is known that the human resources management within the military organization must become a proactive and forward-looking, acting consciously, voluntarily at the structural element of the military organizational culture, or even on it, as a whole. Moreover, the changes within the professional field force the army to adapt in a continuous way relying on its specialized structures.

As a conclusion, at the end of the article, we want to briefly highlight some of the arguments supporting the need to assess organizational culture within the military organization:

- Favouring the selection and acceptance, within the Army, of future human resources compatible in terms of the desired values;

- Developing increased staff management practices significant retention of military personnel within the organization;

- Alignment of the military organization to the proposed image standards;

- From the perspective of organizational culture, human resources management can be directed toward a conscious and efficient alignment of human capital with the desirable values promoted by the military organization.

We also consider that in this professional organization defined by a special mission in Romanian society, it is necessary to have developed a segment, inside the human resources component, aimed at analysing and evaluating the organizational culture. We consider appropriate to develop managerial practices that balance the relationship between human resources management and military organizational culture.

\section{REFERENCES}

Chandler, N. (2018). A Symbiotic Relationship: HR and Organizational Culture, available at: https://www.researchgate.net/publicatio/320674822 A_Symbiotic Relationship HR and Organizational Culture, accessed on 09 September 2020.

Erhart, M.G., Schneider, B., \& Macey, W.H. (2014). Organizational Climate and Culture - An Introduction to Theory, Research, and Practice. New York: Routledge, Taylor and Francis Group.

Mayo, A. (2014). Valoarea umană a organizațiilor. Bucharest: BMI Publishing.

Mărgineanu, V. (2018). Inființtarea Centrului Național Militar de Psihologie și Sănătate Comportamentală în Managementul resurselor umane în Armată. $2^{\text {nd }}$ Edition, No. 14, Bucharest.

Senyucel, Z. (2009). Managing the Human Resources in the $21^{\text {th }}$ Century. Zorlu Senycel and Ventus Publishing Aps. 